\title{
Human Embryonic Stem Cells and Cardiac Repair
}

\author{
Wei-Zhong Zhu, PhD ${ }^{a}$, Kip Hauch, PhD $^{b}$, Chunhui Xu, PhD ${ }^{\mathrm{C}}$, and Michael A. Laflamme, MD, \\ $\mathrm{PhD}^{\mathrm{a}}$ \\ aDepartment of Pathology, University of Washington, Seattle, WA 98109
}

bDepartment of Bioengineering, University of Washington, Seattle, WA 98109

cGeron Corporation, 230 Constitution Drive, Menlo Park, CA 94025

\begin{abstract}
The muscle lost after a myocardial infarction is replaced with non-contractile scar tissue, often initiating heart failure. Whole-organ cardiac transplantation is the only currently available clinical means of replacing the lost muscle, but this option is limited by the inadequate supply of donor hearts. Thus, cell-based cardiac repair has attracted considerable interest as an alternative means of ameliorating cardiac injury. Because of their tremendous capacity for expansion and unquestioned cardiac potential, pluripotent human embryonic stem cells (hESCs) represent an attractive candidate cell source for obtaining cardiomyocytes and other useful mesenchymal cell types for such therapies. hESC-derived cardiomyocytes (hESC-CMs) exhibit a committed cardiac phenotype and robust proliferative capacity, and recent testing in rodent infarct models indicates that they can partially remuscularize injured hearts and improve contractile function. Although the latter successes give good reason for optimism, considerable challenges remain to the successful application of hESCs to cardiac repair, including the need for preparations of high cardiac purity, improved methods of delivery, and approaches to overcome immune rejection and other causes of graft cell death. This review will describe the phenotype of hESC-CMs and preclinical experience with these cells and will consider strategies to overcoming the aforementioned challenges.
\end{abstract}

\section{Index Words}

Stem cell; embryonic stem cell; cardiac repair; transplantation; myocardial infarct

\section{Introduction}

The adult human heart has limited intrinsic regenerative capacity, and so the myocardium lost after a myocardial infarct is typically replaced by non-contractile scar tissue, often initiating congestive heart failure. The prognosis after diagnosis of congestive heart failure remains poor, with one recent study estimating a median survival of 1.7 years in men and 3.2 years in women [1]. In many instances, the only effective therapy for end-stage ischemic heart disease is cardiac transplantation. Unfortunately, the number of available donor hearts approximates 2500 in the U.S. per year, well below the estimated 25,000 patients who would benefit from cardiac

\footnotetext{
For correspondence, please contact: Michael A. Laflamme, MD, PhD, Department of Pathology, Center for Cardiovascular Biology, Institute for Stem Cell \& Regenerative Medicine, University of Washington, 815 Mercer Street, Seattle, WA 98109, Phone: (206) 897-1518, Fax: (206) 897-1540, Email: laflamme@u.washington.edu.

Publisher's Disclaimer: This is a PDF file of an unedited manuscript that has been accepted for publication. As a service to our customers we are providing this early version of the manuscript. The manuscript will undergo copyediting, typesetting, and review of the resulting proof before it is published in its final citable form. Please note that during the production process errors may be discovered which could affect the content, and all legal disclaimers that apply to the journal pertain.
} 
transplantation [2]. Given this, much attention has recently been directed at cell transplantation strategies as an alternative strategy to ameliorate cardiac injury [3-6]. A number of candidate cell types have been considered for such therapies, including skeletal myoblasts [7-9], bone marrow-derived hematopoietic stem cells [10], mesenchymal stem cells [11-14], intrinsic cardiac stem cells [15-18], and embryonic stem cells [19-23]. Of these, skeletal myoblasts and bone marrow derived cells have undergone the most extensive testing in humans, but Phase I and II clinical trials to date have yielded mixed results [24-30]. Moreover, although both skeletal myoblasts and bone marrow derived hematopoietic cells were initially asserted to have cardiomyogenic potential, recent preclinical studies have cast doubt on those conclusions [31-34].

Thus, the search for the "best" candidate cell type for cell-based cardiac repair continues. In reality, the ideal cell source will likely vary with the clinical context, but one can still posit those properties that might be expected of this hypothetical ideal cell. First, the optimal cell should have myogenic and/or angiomyogenic potential in order to replace lost tissue elements, or it must have the capacity to otherwise favorably influence the function of the injured recipient heart via indirect, "paracrine" effects [5]. Second, the cell preparation should be either readily available or obtained via straightforward, reproducible protocols, and it must be scaleable to clinically relevant cell numbers. Indeed, if a candidate cell therapy cannot be reproducibly isolated and used in preclinical studies by multiple sophisticated research labs, it is difficult to imagine its successfully reaching widespread clinical application. Third, the ideal cell preparation must be able to survive the rigors of harvesting, delivery, and survival within the hostile environment of the infarcted heart and must do so in sufficient numbers to mediate a functional benefit. Finally, the ideal cell should either be autologous or minimally immunogenic, or the functional benefits of its use should clearly outweigh the adverse consequences of chronic immunosuppressive therapy.

While none of the currently available candidate cell types for cardiac repair appear to meet all of the aforementioned criteria, pluripotent human embryonic stem cells (hESCs) and their differentiated progeny possess many of these attractive qualities. First, in contrast to many adult stem cell types for whom this capacity is controversial, hESCs have unquestioned cardiomyogenic potential [35-37]. hESCs can also be differentiated into non-cardiac cell types present in myocardium (for example, endothelial cells), suggesting hESCs might eventually be useful in repopulating all myocardial tissue elements, not just cardiomyocytes. Second, $\mathrm{hESCs}$ can be isolated and maintained by well-established protocols, and they are tremendously scaleable. Undifferentiated hESCs retain their phenotype through as many as one hundred population doublings, and, after differentiation, hESC-derived cardiomyocytes (hESC-CMs) exhibit robust proliferative capacity both in vitro $[35,38,39]$ and in vivo [40]. Third, a number of recent reports have shown that hESC-CMs survive after transplantation into infarcted rodent hearts, form stable cardiac implants, and result in preserved contractile function [19,21,22]. Improved methods to deliver cells and enhance their survival post-transplantation will certainly be required, but this is true for all cell-based cardiac therapies. Finally, concerns about immune rejection of hESC-derivatives must be addressed by the field if therapies involving these cells are to reach eventual clinical application. Here, we describe the phenotype of hESC-CMs, consider approaches to deriving highly purified cardiac preparations from hESCs, and review preclinical transplantation studies and the substantial hurdles that remain to their clinical application for cardiac repair.

\section{Human embryonic stem cells}

\subsection{Derivation, culture, and phenotype of undifferentiated human embryonic stem cells}

Although murine ESCs (mESCs) were isolated over 25 years ago [41,42], it was only in 1998 that Thomson and his colleagues successfully derived hESCs from the inner cell mass of pre- 
implantation stage human blastocysts [43]. As with their murine counterparts, undifferentiated hESCs are capable of seemingly unlimited self-renewal by symmetric cell division, but they are also defined by their ability to divide asymmetrically and differentiate into elements of all three primary germ layers (i.e. endoderm, ectoderm, mesoderm). As such, the pluripotency of $\mathrm{hESCs}$ can be confirmed by their ability to give rise to a benign teratoma after transplantation into an immunodeficient animal model. Moreover, given appropriate culture conditions, hESCs have been induced to differentiate into a variety of useful somatic cell types, including neurons, glia, $\beta$-pancreatic cells, hepatocytes, cardiomyocytes, and many others (for review, see [44]). Not surprisingly, these characteristics have generated tremendous interest in the potential use of hESCs as a model of human development, a tool for drug discovery, and a cell source for regenerative medicine.

Because one of the primary potential advantages of hESC-based cell therapies is their tremendous expandability in the undifferentiated state, some brief discussion of the maintenance and propagation of undifferentiated hESCs is warranted. hESCs were initially cultured by growth on a feeder layer of mouse embryonic fibroblasts. Factors released by the feeder cells, which are not fully characterized, support the proliferation and self-renewal of hESCs. Although sufficient for many research applications, it was recognized early on that the direct co-culture of hESCs and non-human feeder cells would be suboptimal for transplantation applications, prompting the development of a feeder-free, conditioned medium system [45] and human feeder cell alternatives [46-48]. More recently, an improved understanding of the signaling molecules involved in hESC self-renewal and expansion (e.g. basic fibroblast growth factor (bFGF) [49,50]) have allowed the development of culture systems using chemicallydefined media [51,52]. Collectively, these developments promise to simplify the process of converting hESC culture conditions suitable for the research lab to the reliable, large-scale, zoonotic pathogen-free, and good manufacturing practice requirements of clinical applications.

Techniques for the isolation of hESCs from blastocyst-stage human embryos have been extensively reviewed by others [53,54], and so are not further discussed here. Although the currently available hESC lines have been derived from blastocyts left over from in vitro fertilization procedures that were otherwise slated for discard, continuing ethical concerns have resulted in efforts to develop alternative, non-destructive approaches to derive hESCs, for example, using blastomere "biopsies" from morula-stage embryos [55]. More recently, two groups independently reported the derivation of ESC-like, induced pluripotent stem cells (iPSCs) by reprogramming adult human fibroblasts via retroviral delivery of four defined factors [56,57]. Although technical concerns remain (principally related to the risks of viral transduction), human iPSCs exhibit a phenotype very similar to hESCs, while avoiding ethical controversies. They could also potentially be used in transplantation medicine in an autologous fashion.

\subsection{Phenotype of human embryonic stem cell derived cardiomyocytes}

Doetschman et al. [58] were among the first to show that, by removing mESCs from conditions supporting pluripotency, they can be induced to form cystic, three-dimensional aggregates, socalled "embryoid bodies," that will include foci of rhythmically contracting cardiomyocytes. Subsequently, numerous laboratories have reported the successful derivation of cardiomyocytes from hESCs, via embryoid body differentiation $[35,37]$ as well as more recently described guided differentiation approaches [19,36] (discussed in more detail below). hESC-CMs variably exhibit spindled, rod-shaped, spherical, and tri- or multiangular morphologies [35-37,39], and they have expected ultrastructural features, including sarcomeres and intercalated discs [37,39,59]. Moreover, as hESC-CMs mature during in vitro embryoid body differentiation, the quantity of myofibrils increases and their arrangement changes from random to parallel alignment [39]. As demonstrated by RT-PCR and 
immunohistochemical studies, hESC-CMs expresss a number of early cardiac-specific transcription factors including Nkx2.5, GATA4, myocyte enhancer factor 2C (MEF2C) and the T-box transcription factors Tbx-5 and Tbx-20 [35,37,39,59-61]. They also express sarcomeric proteins (e.g. $\alpha$-actinin, cardiac troponins I and T, sarcomere myosin heavy chain, atrial- and ventricular- myosin light chains, desmin, and tropomyosin [35-37,60-62]) and other cardiac or muscle-specific proteins (e.g. atrial natriuretic peptide, creatine kinase-MB and myoglobin [35,37]). (See Figures 1A \& B.) Mature myocardium is an electrical synctitium, and, as expected, immunocytochemical studies on hESC-CM cultures demonstrate that connexins and cadherins (elements of gap junctions and adherens junctions, respectively) are present at points of contact between adjacent myocytes [35-37,63,64].

As has been previously shown in electrophysiologic studies of mESC-derived cardiomyocytes [65], hESC-CMs exhibit diverse electrophysiologic signatures that include cells with distinct nodal/pacemaker-, atrial, and ventricular-like action potential properties [36,62]. (See Figure 1C.) At least at early stages of in vitro maturation, $\mathrm{hESC}-\mathrm{CMs}$ exhibit electrophysiologic characteristics of primitive myocardium, including a comparatively low action potential upstroke velocity and a depolarized maximum diastolic potential, but these parameters appear to transition toward somewhat more mature values with increasing duration in culture [62, 66]. Voltage-clamp studies indicate that several cardiac-specific currents are present in these cells, including fast sodium current, L-type calcium current, pacemaker currents, as well as transient outward and inward rectifier potassium currents $[36,66,67]$. As in more mature cardiomyocytes, the trigger for contraction in hESC-CMs is a rise in intracellular calcium, and these cells do exhibit calcium transients [36] (See Figure 1D). That said, some investigators have suggested that these cells have significantly different mechanisms of calcium handling than that in adult cardiomyocytes, such that virtually all of the calcium transient results from trans-sarcolemmal entry via calcium channels rather than by release from internal stores [68, 69]. The latter observation has not held true in our hands - in preliminary studies, we found a robust contribution to the calcium transient in these cells from both L-type calcium channels and ryanodine-sensitive, sarcoplasmic reticulum calcium stores (Zhu, Santana, and Laflamme, unpublished data). Finally, hESC-CMs show at least some of the neurohumoral regulation expected of mature myocardium. For example, treatment with the $\beta$-adrenergic agonist isoproterenol has been shown to induce concentration-dependent increases in the magnitude and frequency of their contraction $[35,37,62,70]$.

\subsection{Other differentiated progeny of human embryonic stem cells of potential use in cardiac repair}

If the goal of cell-based therapies is to truly replace myocardial tissue (as opposed to simple replacement of cardiomyocytes), delivery of other cell types may be required. Indeed, while contributing the majority of the structural volume of the heart, cardiomyocytes comprise only approximately one-third of the total cell number, with the balance being largely accounted for by fibroblasts, endothelial cells, and smooth muscle cells [71]. Moreover, a number of in vitro studies with engineered heart tissues have suggested improved viability, tissue organization, and functional performance in constructs that include an admixture of cell types, rather than just cardiomyocytes alone [72]. Thus, one of the potential advantages of hESC-based therapies is that the latter represent a single potential source for deriving multiple useful differentiated cell types. In addition to cardiomyocytes, hESCs can also be successfully differentiated into potentially useful non-cardiac cell types. For instance, hESCs can be differentiated into endothelial cells by vascular endothelial growth factor (VEGF) [73] and enriched from differentiating cultures by fluorescence-activated cell sorting (FACS) with platelet endothelial cell-adhesion molecule-1 (PECAM1) antibodies [74]. hESC-derived endothelial cells exhibit expected endothelial markers (including PECAM1, CD31, VE-cadherin, and GATA-2), metabolize acetylated low-density lipoprotein, and form vessel-like structures both in matrigel 
plugs in vitro and subcutaneous implants in immunodeficient mice. hESC-derived smooth muscle cells, which reportedly can be induced by platelet-derived growth factor (PDGF) [73] and all-trans retinoic acid [75], express expected markers including smooth muscle $\alpha$-actin, smooth muscle myosin heavy chain, calponin, smoothelin, SM22 $\alpha$, telokin and myocardin. They exhibit a contractile phenotype and respond to agonists including carbachol [76].

\section{Approaches to the generation of highly purified hESC-CMs}

\subsection{Cardiomyocyte differentiation from ESCs and embryonic cardiac development}

Studies with both mESCs and hESCs suggest that their differentiation into cardiomyocytes in vitro mimics events during embryonic development [61,77]. Indeed, the temporal regulation of cardiac-associated genes in differentiating hESC-CMs recapitulates that of embryonic cardiogenesis [61]. During early stages of hESC differentiation, markers of pluripotency such as Cripto, telomerase reverse transcriptase (TERT), and the transcription factor Oct3/4 are down-regulated, while Brachyury, a T-box transcription factor and a marker of newly-formed mesoendoderm, is upregulated. Shortly thereafter, early cardiac markers such as Nkx2.5, MEF2C and Tbx5 appear. Later during differentiation, there is increased expression of later cardiac markers, such as cardiac $\alpha$ myosin heavy chain, cardiac $\beta$ myosin chain and atrial natriuretic factor. This orderly sequence of cardiac gene expression reinforces the hope that the vast knowledge gained from developmental biology will be instructive to the challenging task of efficiently deriving cardiomyocytes from hESCs.

Heart development in vertebrate embryos proceeds through a series of complex, highly regulated processes, including early specification of cells into cardiac lineage, proliferation and differentiation of progenitors, and morphogenesis of the heart. Recent studies have shown that cardiogenesis involves two separate progenitor cell populations or "heart fields" that arise from a common progenitor present during gastrulation (for review see [78]). Soon after gastrulation, the earliest cardiac progenitors migrate from the epiblast and are specified in the anterior lateral plate mesoderm (precardiac mesoderm) to form the primary heart field. These cells give rise to the cardiac crescent, which is fated to contribute to the left ventricle and atria. Cells from the cardiac crescent then migrate medially and fuse to form the primitive linear cardiac tube, which obviously must undergo extensive morphological changes before forming the mature heart. The second heart field, which is derived from pharyngeal mesoderm cells located medial to the cardiac crescent, also contributes to the formation of the heart, most significantly to the right ventricle and outflow tract. The primary and secondary heart fields can be distinguished based on their expression of unique molecular markers, although they certainly have many others in common (e.g. Nkx2.5). For example, the primary heart field expresses the transcription factors Tbx 5 and Hand 1 (heart and neural crest derivatives expressed protein-1), while the secondary heart field expresses the transcription factor Islet-1 (Is11) and fibroblast growth factor-10 (FGF-10) $[79,80]$.

In addition to cardiomyocytes, smooth muscle cells and endothelial cells also contribute to heart formation. Interestingly, multipotent progenitors common to these cells have recently been uncovered in early mouse embryos and mESCs, based on the progenitors' temporally regulated expression of Flk-1 tyrosine receptor kinase (otherwise known as vascular endothelial growth factor receptor 2). In particular, it appears that an early Flk-1\%/Brachyury+ progenitor can give rise to two distinct populations of Flk-1+/Brachyury+ progenitors: one that contributes to endothelial cells and blood cells, and the other capable of differentiating into diverse types of cells in the heart, including endothelial cells, cardiomyocytes and smooth muscle cells [81]. Isl1+/Nkx2.5+/Flk-1+ progenitors from the secondary heart field of early mouse embryos can also give rise to cardiac, smooth muscle and endothelial cells in vivo, and analogous multipotent cardiovascular progenitors isolated from mESCs have been shown to differentiate into endothelial cells, cardiomyocytes and smooth muscle cells as well [82]. 
Similarly, Nkx2.5+/ckit+ progenitors isolated from early mouse embryos and mESC cultures can differentiate into both cardiomyocytes and smooth muscle cells [83]. The molecular mechanisms that direct these shared progenitors into specific lineages still remain largely undefined, however.

\subsection{Factors influencing cardiogenesis}

Early experiments with model systems of embryonic development demonstrated that cardiogenesis is regulated by factors provided by adjacent tissue structures. For example, in the developing avian heart, the pregastrula hypoblast (extra-embryonic endoderm) is capable of inducing cardiogenesis from cells in the epiblast [84]. Cells in the cardiac mesoderm, located in the anterior primitive streak, interact with the adjacent anterior endoderm and differentiate into beating cardiomyocytes $[85,86]$. Furthermore, the anterior endoderm has the ability to induce cardiogenesis from cells not only of cardiac mesoderm but also non-cardiac mesoderm $[86,87]$.

This cardio-inductive activity exhibited by anterior endoderm can be at least partially mimicked by a number of growth factors, including several belonging to the transforming growth factor$\beta$ (TGF $\beta$ ) superfamily, such as activin A, TGF $\beta$, and bone morphogenetic proteins (BMPs) $[88,89]$. For instance, application of BMP2 or BMP4 to structures adjacent to the heart-forming region in chick embryos induce ectopic expression of key cardiac transcription factors (i.e. Nkx2.5 and GATA-4) and the formation of beating cardiomyocytes, while the BMP antagonist noggin is capable of inhibiting differentiation of the precardiac mesoderm [90,91]. This critical role of BMPs in cardiogenesis has also been documented in in vitro studies with differentiating mESCs [92] or P19 murine embryonal carcinoma cells [93-95]. Furthermore, Nodal, another TGF $\beta$ family member, and its co-receptor Cripto play a significant role in cardiac development. Cripto-1 is initially expressed in trophoblasts and the inner cell mass of mouse blastocysts, but its expression subsequently becomes restricted to developing myocardium [96,97].

Inactivation of Cripto arrests cardiogenesis in both mouse embryos [98] and mESCs [99], while enhancing neurogenesis [100]. In zebrafish, Nodal induces expression of Casanova, a Soxrelated transcription factor that induces the formation of cardiac-inducing endoderm [101].

Multiple members of the Wnt/wingless family of signaling molecules are also known to play an essential role in cardiac development. Some confusion has arisen regarding the function of Wnt ligands in cardiogenesis because of the diverse temporal and species-specific activities of these signaling pathways. Hence, canonical (i.e. $\beta$-catenin-mediated) Wnt signaling is reported to exert positive and negative influences on cardiac development in different model systems. In the avian model, canonical Wnt signaling functions as an inhibitor of cardiogenesis [102-106], while, conversely, the Wnt antagonist Crescent promotes cardiogenesis in posterior non-cardiac mesoderm [107]. A similar inhibitory effect is observed in the Xenopus model, where overexpression of Wnt3A or Wnt8 represses cardiogenesis in cardiac mesoderm [108], while Wnt antagonists and GSK-3 $\beta$ again induce cardiogenesis in non-cardiogenic mesoderm. By contrast, $\beta$-catenin mediated Wnt signaling promotes cardiogenesis in P19 cells [109] and mESCs [110]. These seemingly discrepant results can perhaps be resolved in part by considering the time dependency of Wnt/ $\beta$-catenin signaling. Indeed, in both the zebrafish model and in mESCs, canonical Wnt signaling promotes cardiogenesis during early stages of differentiation, while opposing it at later stages $[111,112]$. Finally, a role for non-canonical Wnt signaling has also been proposed, as the non-canonical Wnt ligand, Wnt11, promotes cardiogeneis in Xenopus embryos [113], P19 cells [113], and mESCs [111,114].

Growth factors not belonging to either the TGF $\beta$ or Wnt signaling families have also been implicated in cardiogenesis. FGF, insulin, and insulin-like growth factors have each been reported to induce the formation of functional cardiomyocytes from pre-cardiac mesoderm $[89,115-117]$ or to induce proliferation of precardiac mesoderm and to enhance cardiac 
development [115]. Platelet-derived growth factor [118] and erythropoietin [119] are known to be involved in cardiogenesis in both mouse embryos and mESCs. Oxytocin, a welldocumented cardio-active hormone [120], can stimulate cardiac differentiation in P19 cells [121] and cardiac stem cells [122], possibly through nitric oxide signaling [123].

Finally, it is worth noting that there is good evidence supporting the inhibitory role of Notch signaling pathways on cardiac differentiation. Notch activation suppresses cardiac development in both Xenopus [124] and chick embryos [125]. In mESCs, Notch appears to influence the cell fate decision between the cardiogenic and neural lineages. Blockade of Notch signaling enhances mesodermal and cardiogenic commitment, while activation of Notch signaling prevents cardiogenesis but promotes neural differentiation [126,127].

\section{3. "Guided" cardiac differentiation of hESCs}

There is widespread consensus that, if hESCs are to have a future in cell-based cardiac repair, the field must substantially improve the efficiency by which cardiomyocytes can be generated from $\mathrm{hESCs}$. Until quite recently, the typical method for obtaining hESC-CMs was to form embryoid bodies (in medium including a relatively high fraction of fetal calf serum) and then harvest the resultant, spontaneously contractile cardiomyocytes by either mechanical dissection [37] or enzymatic methods [35]. Embryoid bodies contain an admixture of many differentiated cell types, and so cardiogenesis is woefully inefficient by this approach. Indeed, in our hands, somewhat less than $1 \%$ of the total differentiated cell population in large-scale embryoid body outgrowth cultures exhibits a cardiac phenotype $[19,40]$. Although such relatively impure cardiac preparations can be further enriched by other methods (see below), considerations of safety and scalability point to the need for a more homogenously cardiac population. Fortunately, the large body of knowledge regarding cardiogenesis in model systems (reviewed in the previous section) provides reassurance that guided cardiac differentiation of $\mathrm{hESCs}$ is possible, and it suggests many candidate approaches.

Early efforts to induce cardiogenesis in hESCs have generally focused on the use of either endoderm or factors known to be released by endoderm during development. An early success in this direction was reported by the Mummery group, who found that co-culture with END-2 cells, a murine visceral endoderm-like cell line, was sufficient to coax some degree of cardiac differentiation by several hESC lines incapable of forming embryoid bodies [36]. By eliminating serum from medium used during the co-culture, these investigators were able to further enhance cardiogenesis, generating preparations of 5-20\% hESC-CMs [128].

Our group has focused on identifying defined factors to enhance the differentiation of hESCCMs. Based on an extensive screening effort involving many factors implicated in mesodermal and/or cardiac differentiation in model systems, we have developed a guided cardiac differentiation protocol that involves two members of the TGF $\beta$ superfamily of growth factors, activin A and BMP4 [19]. In this approach, hESCs are maintained in monolayer culture in their usual undifferentiated growth medium (e.g. mouse embryonic fibroblast conditioned medium [45]) for approximately one week, after which they are sequentially treated with activin A and BMP4 in serum-free medium. The growth factors are then removed, and the cells are maintained in serum-free medium for an additional 2-3 weeks. This procedure typically yields preparations of $>30 \%$ cardiomyocytes, again versus the $<1 \%$ cardiac preparations obtained using "spontaneous" embryoid body differentiation. Foci of spontaneously contracting cardiomyocytes are usually observed approximately one week after withdrawal of the growth factors, and they show sustained contractile activity even after several weeks in culture. The cardiac phenotype of these myocytes has been extensively validated by immunohistochemistry, RT-PCR, and functional studies. (In fact, the examples depicted in Figure 1 were obtained with hESC-CMs generated with this approach.) Furthermore, this preparation of directly differentiated $\mathrm{hESC}-\mathrm{CMs}$ has been validated for its ability to remuscularize infarcted rat hearts 
and help preserve cardiac function (for more details, see ref [19] and below). Finally, Takahashi et al. [129] reported that our guided cardiac differentiation protocol with activin and BMP4 is efficacious with their recently described human iPSCs. This report gives us hope that ongoing work with hESCs will inform efforts to guide the differentiation of this exciting new source of pluripotent cells.

Other investigators have also explored the cardiac induction of hESCs using growth factors belonging to the TGF $\beta$ superfamily. Tomescot et al. [23] reported a three- to ten-fold increase in the expression of mesodermal and cardiac genes during hESC embryoid body differentiation with the application BMP2 and SU5402, a FGF receptor inhibitor. Burridge et al [130] added activin A and FGF2 during early embryoid body differentiation and found that these factors resulted in an approximately five-fold increase in the percentage of spontaneously beating foci. Both studies underscore the essential role of TGF $\beta$ superfamily members in the cardiac differentiation of hESCs, but they provide apparently conflicting results with regard to FGF. We speculate that the latter difference may reflect other differences in terms of the cell lines employed, culture conditions, and the timing of treatment, but more study of FGF signaling in this context is clearly warranted.

To this point, we have emphasized the value of insights from embryogenesis in model systems in the development of guided cardiac differentiation protocols for hESCs. Signaling cascades critical to cardiogenesis in other stem cell types provide another attractive source of candidate molecules to optimize the in vitro derivation of cardiomyocytes from hESCs. For example, ascorbic acid, reported to improve cardiomyogenic differentiation by mESCs [129] and human bone marrow stem cells [131], also enhances cardiogenesis in hESCs [128]. 5-aza-2'deoxycytidine (5-aza-dC) enhances the cardiomyogenic differentiation by mesenchymal stem cells [132-134], resident cardiac stem cells [16,122], and P19 embryonal carcinoma cells [135]. 5-aza-dC, which presumably works via demethylation of DNA, also promotes the differentiation of hESCs into cardiomyocytes [35,136].

On the other hand, it should be emphasized that hESCs have unique properties relative to model systems and other stem cell types, and so it follows that not all factors and approaches implicated in these systems will prove efficacious in the differentiation of hESCs into cardiomyocytes. Indeed, dimethyl sulfoxide and all-trans retinoic acid, which are strong cardiogenic inducers in P19 cells [137] and mESCs [138], respectively, fail to enhance cardiomyogenic differentiation in hESCs [35]. Conversely, it is possible that novel factors not anticipated by work in model systems may prove useful with hESCs. Finally, it should be emphasized that different hESC lines exhibit somewhat different behavior, and they vary in the efficiency in which they differentiate into cardiomyocytes. For instance, cardiomyogenic differentiation of hES1, hES2, hES3 and hES4 hESC lines can be induced by co-culture with endoderm [36,139], but not through embryoid body formation as has been shown with the H1, H7, H9 and H14 hESC lines [140,141]. The bottom line: while the developmental biology and stem cell literature can be helpful, they do not eliminate the need for the empirical testing of candidate cardiomyogenic factor(s) in hESCs (ideally, across multiple hESC lines).

\subsection{Enrichment of ESC-derived cardiomyocytes}

Even the best available protocols for the guided cardiac differentiation of hESCs do not result in a homogenous preparation of cardiomyocytes, but rather produce an admixture of multiple cells types with cardiomyocytes typically comprising a plurality. Thus, additional enrichment step(s) may be required for in vivo applications, at least given our present incomplete understanding of hESC differentiation. Several approaches to the enrichment of cardiomyocytes from differentiated hESC cultures have been explored. In one method, undifferentiated hESCs are genetically modified to carry a mammalian selection gene (e.g. antibiotic resistance) under the control of a cardiac-specific promoter. The modified cells are 
then induced to differentiate and then selected based on activation of the cardiac-specific promoter. Early proof of principle for this approach was provided by the Field group [142], who generated preparations of cardiomyocytes of $>99.6 \%$ purity from mESCs bearing a transgene in which expression of the aminoglycoside phosphotransferase gene (i.e. neomyocin resistance, which confers resistance to the antibiotic G418 in mammalian cells) was driven by cardiac-specific $\alpha$-myosin heavy chain promoter with selection of differentiated cardiomyocytes. This selection strategy was subsequently adapted to generate and purify mESC-derived cardiomyocytes on a large scale $[143,144]$. A related approach, which has proven useful with both mESCs [145] and hESCs [146,147], involves expression of green fluorescent protein (GFP) under a cardiac-specific promoter and enrichment of cardiomyocytes by FACS. For example, the Gepstein group has generated preparations of hESC-CMs of $>93 \%$ purity and $>85 \%$ viability, based on FACS of myocytes expressing eGFP under the human myosin light chain-2V promoter [147].

Genetic selection represents an impressive technology by which to enrich cardiomyocytes from $\mathrm{hESCs}$, but it entails the usual risks of gene therapy (e.g. insertional oncogenesis). It is unclear how regulatory agencies will approach the dual concerns of genetic modification and the use of a novel pluripotent cell type. On the other hand, there are other enrichment methods that take advantage of the unique immunophenotypic and/or physical properties of cardiomyocytes (or cardiac progenitors) and so do not require genetic modification. Native cell surface markers are often targeted to select specific cell types via FACS or magnetic cell separation, but as yet no cardiomyocyte-specific surface markers have been reported or used with hESCs. Still, as discussed above, multipotent cardiac progenitors have been isolated from mESCs via FACS for the cell surface marker Flk-1, and these progenitors have subsequently been induced into cardiomyocytes at high purity [81]. This approach may be applicable to hESCs, if similar progenitors can be identified based on Flk-1 or other markers. Another method of enrichment for hESC-CMs that our own group has successfully employed is Percoll gradient separation, a technique that relies on the unique buoyant properties of cardiomyocytes. Differential cell densities can be separated via Percoll gradient centrifugation, and, in our hands, this technique typically results in a three- to seven-fold enrichment of hESC-CMs when applied to enzymatically dispersed cells from embryoid bodies $[35,40]$ or cultures "guided" by treatment with activin A and BMP4 [19]. One final strategy that we have found helpful in the enrichment of hESC-CMs involves the formation of suspended aggregates of differentiated cells, structures we have termed "cardiac bodies" [148]. Even after enzymatic dissociation of embryoid bodies to single cells, hESC-CMs (and other non-cardiac cells present) will re-associate in suspension cultures to form the aforementioned cardiac bodies. Cardiomyocytes survive exceedingly well under these conditions and, in fact, out-compete the non-cardiac cells, eventually resulting in cardiac bodies that are comprised of $>60 \%$ cardiomyocytes.

As a final note, it is worth commenting on the various methods by which the cardiac purity of hESC-derived preparations have been assessed. A large number of endpoints have been used in making this assessment, ranging from simple counts of the number of spontaneously beating foci, to RT-PCR or Western blotting for cardiac markers, to quantitation of the percentage of cells expressing cardiac-specific markers (e.g. sarcomeric proteins) by immunocytochemistry or flow cytometry. This diversity in endpoints often makes it difficult to compare the degree of cardiac enrichment obtained by different approaches in different labs. We now have multiple protocols resulting in near-homogenous preparations of hESC-CMs $[19,147,149]$, and these are the benchmark to which alternative strategies should be compared. Thus, while we recognize that more convenient endpoints (e.g. beating, RT-PCR) may be useful for rapid screening, we would encourage investigators in the field to report the absolute fraction of the total cell population that is positive for cardiac markers whenever possible. 


\section{Cardiac repair with human embryonic stem cells}

\subsection{Proof of principle from transplantation studies using embryonic, fetal, and neonatal cardiomyocytes}

Operating on the intuitive assumption that the logical cell type to replace lost cardiomyocytes would be cardiomyocytes themselves, the first preclinical studies of cell-based cardiac repair employed terminally-differentiated myocytes from embryonic, fetal, and neonatal hearts [150-155]. These studies provided invaluable early proof-of-principle for the field, as the implanted cells formed stable intracardiac grafts, retained their cardiac phenotype (including expression of expected sarcomeric and gap junction proteins), and resulted in improved left ventricular function. By comparison, adult cardiomyocytes showed very poor survival posttransplantation [156], indicating that less mature myocytes may be intrinsically more robust and better suited to persist in the hostile graft environment. Of course, practical considerations related to supply and ethical concerns essentially preclude the clinical application of cardiomyocytes from human fetal or neonatal sources.

Using the genetically selected preparation described above, the Field group was the first to demonstrate that the transplantation of mESC-derived cardiomyocytes into the uninjured hearts of immunocompatible mice resulted in the formation of stable intracardiac grafts [142]. By implanting wildtype cells into dystrophin-null recipients, these authors were able to use dystrophin immunohistochemistry to show surviving graft cardiomyocytes, with sarcomeric organization in alignment with host myofibers, for as long as 7 weeks. The Xiao group were the first to demonstrate the survival of mESC-derived cardiomyocytes after transplantation in infarcted hearts [157,158], and they and others [159-161] have shown that this cell therapy attenuates the progressive loss of cardiac function by injured hearts using echocardiography and other parameters. Of note, in one of the aforementioned studies [159], these functional benefits were observed with transplantation of mESC-derived cardiomyocytes but not bone marrow derived hematopoietic cells, another candidate cell type for cardiac repair.

Terzic and co-workers have transplanted undifferentiated mESCs, a cell preparation that one would expect to give rise to teratomas, into the infarcted hearts of allogeneic mice and immunocompetent rats $[162,163]$. They observed similar functional benefits, and, surprisingly, reported that the implanted cells preferentially differentiated into mature cardiomyocytes, indistinguishable from those of the host. If correct, their results would have two remarkable implications: first, that the implanted cells somehow escape immune recognition (plausible for undifferentiated cells, but unexpected for their differentiated progeny); and, second, that the recipient heart is an instructive, cardiogenic environment. Unfortunately, we and others have been unable to reproduce these results and, instead, find that the transplantation of undifferentiated mESCs into immunodeficient or syngeneic hosts produce teratomas [159, $164,165]$, while mismatched grafts result in immune rejection [164,165]. Thus, in our opinion, use of ESCs implies a need to deal with both the immune system and the risk of teratoma formation.

\subsection{Pre-clinical transplantation studies with hESC-CMs}

Not surprisingly given their more recent derivation, transplantation experience with hESCCMs is more limited than with their murine counterparts. The first two studies were performed in uninfarcted hearts and were intended to demonstrate engraftment and assess the capacity of the implanted cells to undergo electromechanical integration with the host. In separate studies, the Gepstein [166] and Li groups [167] microdissected spontaneously contracting embryoid bodies from hESCs and then transplanted these into immunosuppressed animals (pigs and guinea pigs, respectively) with experimental heart block. Both studies used electrical mapping techniques to show that the site of hESC-CM implantation served as an ectopic pacemaker, 
thereby providing strong evidence for host-graft electromechanical coupling at least in uninfarcted hearts. The Gepstein study also included limited histologic analysis, showing small clusters of surviving cardiac graft cells, positive for both cardiac $\alpha$-actinin and a human-specific mitochondrial marker, for up to 1-3 weeks post-transplant. Our own group tested the ability of hESC-CMs to form human myocardium in uninjured nude (athymic) rat hearts, transplanting a Percoll-enriched preparation of embryoid body outgrowth cells (of $10-20 \%$ cardiac purity) $[35,40]$ and following their fate by histologic endpoints. The grafts in this study were initially quite small, but the implanted cardiomyocytes showed remarkable proliferative activity in vivo (as indexed by BrdU incorporation and cell cycle markers), resulting in seven-fold increase in graft size over 4 weeks. The graft cardiomyocytes, whose human origin was confirmed by in situ hybridization with human-specific DNA probes, exhibited expected cardiac markers, including $\beta$-myosin heavy chain, myosin light chain $2 \mathrm{v}$, and atrial natriuretic factor. No teratomas were observed; moreover, the non-cardiac graft cells disappeared over time, eventually leaving implants comprised of cardiomyocytes and the occasional endothelial cells. The mechanisms underlying this clearance of non-cardiac cell types remain unclear. More recently, Dai et al [63] transplanted a similarly crude preparation of hESC-CMs $(\sim 13 \%$ cardiomyocytes) into uninfarcted nude rats and also found surviving cardiac implants without teratoma formation.

In the past year, a number of labs have reported progress in preclinical studies involving the transplantation of hESC-CMs into the more hostile environment of the infarct zone (Please see Table 1). Our own group demonstrated the capacity of these cells to form stable cardiac implants and favorably influence cardiac function in a nude rat ischemia-reperfusion infarct model [19]. We generated a highly purified preparation of human cardiomyocytes $(\approx 80-85 \%)$, using the directed differentiation protocol described above (i.e. serial activin A and BMP4) followed by Percoll gradient enrichment [19]. When these cells were injected into recently infarcted hearts in the presence of a cocktail of pro-survival factors to limit cell death posttransplantation, they formed stable cardiac grafts within the scarred zones of $100 \%$ of recipient hearts. As before, the human cardiac implants in histologic sections were observed at a 4-week time point, and their origin was confirmed with human-specific in situ probes. The grafts exhibited an expected cardiac immunophenotype, and no teratomas were observed (indeed, vanishingly few non-cardiac human graft cells were found at all). Of note, however, the cardiac implants were small (occupying a mean of only $4 \%$ of the total scar cross-sectional area) and were generally separated from host cardiomyocytes by scar. Nonetheless, echocardiographic and MRI studies indicated beneficial functional effects with hESC-CM grafting: recipients of the latter cells showed attenuated left ventricular dilatation and preserved global and regional contractile function relative to controls receiving vehicle or the pro-survival factors alone. Interestingly, these effects appeared to require the presence of cardiomyocytes, as they were not observed with the transplantation of a non-cardiac, hESC-derived cell preparation.

Caspi et al. [21] recently reported qualitatively similar results with the transplantation of hESCCMs into infarcted rat hearts, although these authors used a different cell preparation (i.e. mechanically dissected beating embryoid bodies) and pharmacologically immunosuppressed, rather than nude rats. In particular, these authors showed surviving graft myocardium for as long as 8 weeks post-transplantation (although the extent of remuscularization was not assessed), as well as improved left ventricular dimensions and function in cardiomyocyte recipients versus controls at 4 - and 8 weeks post-transplantation by echocardiography. As in our own study, the latter functional effects were not observed with differentiated non-cardiac hESC-derivatives (i.e. non-beating areas removed from embryoid bodies. Finally, these authors also showed that transplantation of undifferentiated hESCs resulted in the formation of teratomas. 
Another recent study that warrants particular comment examined the transplantation of hESCCMs in a murine model (i.e. acutely infarcted immunodeficient (NOD-SCID) mice) [22]. In this work, van Laake et al. obtained hESC-CMs by mechanically dissecting beating foci that resulted from co-culture of hESCs and END-2 endodermal cells (see above). Interestingly, although the cardiac purity of the input cell preparation in this study was comparatively low (20-25\% cardiomyocytes), the authors reported that the non-cardiac cells were gradually cleared from the recipient hearts, an observation akin to our own findings with transplantation studies in normal [40] but not infarcted [19] rat hearts. They reported the survival of human graft cells for as long as 12 weeks post-transplantation and beneficial functional effects by MRI on left ventricular dimensions and function 4 weeks post-transplantation. However, a potentially troubling finding from this study is that the latter functional effects appeared transient: the statistically significant differences between cardiomyocyte recipients and controls at 4 weeks post-transplantation were no longer present at 12 weeks. It should be noted that no histomorphometry with regard to graft size was reported at any timepoint in this study, and so the size (and the cardiac phenotype) of the surviving human graft at 12 weeks is unclear. Nonetheless, van Laake et al. included by far the longest duration of follow up with hESC-CM transplantation, and, particularly given recent reports of transient functional benefits in early clinical trials testing bone marrow cells in cardiac repair [29], these results underscore the need to include later timepoints in future preclinical studies.

Important differences in experimental design (e.g. choice of species, method and timing of infarct generation, cell preparation including hESC line employed and mode of differentiation, cell dose, length of follow-up, use of pro-survival factors, etc.) complicates detailed comparisons of the three aforementioned and other recent studies examining hESC-CM transplantation in rodent infarct models. (Please see Table 1 for a brief summary of their respective experimental design and major findings.) That said, they do have a number findings in common that suggest the following provisional conclusions: First, hESC derived cardiomyocytes can engraft and survive in infarcted rodent hearts (at least for as long as 4-12 weeks). Given that these studies involve the delivery of xenogeneic cells with a presumably high metabolic demand into a poorly vascular, pro-inflammatory infarct environment, this is no small feat. In our own hands, this graft survival required co-delivery with pro-survival factors [19], but other investigators have reported some level of engraftment (generally not quantitated by histomorphometry) without this requirement [20-23,168]. Second, all studies to date that examined functional consequences of hESC-CM transplantation observed beneficial effects on left ventricular remodeling and function. Moreover, three groups independently reported that the transplantation of differentiated non-cardiac hESC derivatives did not mediate these functional effects, demonstrating that not just any cell will suffice and that a specifically cardiac preparation may be required for maximal benefit. Third, while some have suggested preferential cardiac differentiation of ESC derivatives after intra-cardiac transplantation, careful histologic analyses have shown the transplantation of undifferentiated hESCs or differentiated hESC derivatives of low cardiac purity can give rise to teratoma-like graft elements in infarcted hearts [19-21]. Thus, while some investigators continue to pursue the use of undifferentiated hESCs for cardiac repair [169], this is, in our opinion, an unnecessarily risky approach.

A final issue worth considering is the mechanism by which the implanted cells mediated beneficial effects on contractile function. The most straightforward mechanism is that the implanted myocytes undergo appropriate electromechanical integration with the host and directly contribute new force-generating units, but this is by no means the only possibility. As we have reviewed in more detail previously [5], other indirect mechanisms of action have been suggested to explain the functional benefits with other cell-based cardiac therapies, including favorable "paracrine" effects on ventricular remodeling, formation of collaterals, inflammation, or host cell survival. 
This question of mechanism of action is not purely academic; it has important ramifications on the potential for arrhythmogenesis, the appropriate timing of hESC-CM delivery, and the number of surviving cells that may be required to mediate an effect. In favor of graft-host electromechanical coupling, hESC-CMs express gap junctions and have been shown to undergo electromechanical integration (and act as ectopic pacemakers) in uninfarcted hearts $[166,167]$. On the other hand, in our own study of hESC-CM transplantation into infarcted hearts, histologic sections showed infrequent points of host-graft contact, and most of the graft was insulated by scar tissue [19]. It is also unclear whether these human cardiomyocytes are even capable of keeping up with the much more rapidly beating rodent heart ( $\sim 00$ beats/ minute) in these studies. If not, this would imply that a paracrine mechanism underlies the functional benefits observed in rodent studies and suggests that an additional increment of improvement is possible if hESC-CMs can better couple in the more slowly beating human heart. Fortunately, the field has developed elegant electrophysiologic $[170,171]$ and optical $[172,173]$ methods to directly determine whether graft cells are activated in systole, and these important studies are undoubtedly underway.

\subsection{Remaining hurdles to the clinical application of human embryonic stem cells in cardiac repair}

Despite generally encouraging results from preclinical studies with hESC-CMs in rodent models, substantial challenges remain to the development of clinical therapy based on these cells. It is possible that studies in larger, slower-rate preclinical models may identify other unexpected challenges, and, as underscored by the mixed results from recent clinical trials with other candidate cell types for cardiac repair, there can be no substitute for eventual testing in human patients. Still, we here identify what we perceive as the major hurdles to the clinical application of hESC-CMs and discuss potential approaches to overcoming them.

4.3.1 Immune rejection-An important challenge to any therapeutic application involving hESCs or their differentiated progeny will be the need to prevent immunologic rejection of the graft. Studies in murine models show that the immunogenicity of ESCs increases with differentiation, and so cardiac transplants of differentiated ESC-derivatives are recognized and rejected by allogeneic recipients $[164,165]$. Thus, some degree of pharmacologic immunosuppression will likely be required for allotransplants of hESC-CMs. The need for immunosuppression by no means precludes use of hESC-based cell therapies-we currently immunosuppress heart transplant recipients because the benefits to the patient with end-stage heart disease outweigh the intrinsic risks of immunosuppression. Were hESC-CM transplants to prove efficacious in human patients, a similar risk-benefit analysis would be required in this case. However, there is some reason for optimism that preventing rejection of hESC-derivatives might require less intense immunosuppression than is required in the setting of conventional organ transplantation. First, elegant transplantation studies in the humanized (Trimera) mouse model suggest that, while differentiated hESC progeny are immunogenic, they are considerably less so than adult tissues [174]. Second, there is the possibility of banking large numbers of diverse, human leukocyte antigen (HLA) isotyped hESC lines, so as to improve the likelihood of a close match.

That said, it would be obviously desirable to avoid immunosuppression with hESC-based therapies if possible, and a number of investigators have posited potential, but as yet untested approaches for doing so. The reader is referred to an excellent review by Odorico et al. [44], which outlines strategies including nuclear reprogramming to generate an "autologous" hESC cell source, genetic manipulation of major histocompatibility genes to produce a "universal" donor hESC line, and induction of immune tolerance via the transplantation of hESC-derived hematopoietic precursors and establishment of bone marrow chimerism. Finally, as discussed above, the recently reported iPSCs, generated by reprogramming human adult human 
fibroblasts, represent a potential autologous source of cells with an apparently hESC-like phenotype [56,57].

\subsubsection{Host-graft electromechanical integration and potential for}

arrhythmogenesis-A second challenge to the clinical application of hESC-CMs to cardiac repair is their potential for arrhythmogenesis. As noted above, we do not presently know whether these cells become electromechanically coupled with the host muscle after transplantation into infarcted hearts. If the graft cells are not well-coupled, they could promote arrhythmogenesis by introducing points of electrical heterogeneity into the myocardium. On the other hand, if the hESC-CMs are well-integrated, they could still induce rhythm disturbances if their single-cell electrophysiologic properties are sufficiently different from those of the adult host myocardium. Thus, it may be of concern that currently available preparations of hESC-CMs are heterogeneous and include myocytes with ventricular-like but also nodal- and atrial-like action potential properties. Further, even the apparently ventricularlike hESC-derived myocytes show immature electrophysiologic properties and so, relative to adult ventricular myocytes, have a comparatively depolarized maximum diastolic potential, a slower action potential upstroke, and a much smaller cell size. It is uncertain whether these disparities will diminish with in vitro or in vivo maturation.

No arrhythmias or increased mortality to suggest sudden cardiac death has been reported in preclinical studies to date, but all have been performed in rodent models. Rodent heart rates are considerably higher than those of humans (e.g. 300-400 beats per minutes for a rat [175] versus $60-100$ beats per minute for a human), and so could mask arrhythmias generated by pacemaker activity or re-entrant circuits that would still occur in slower heart rate species. Safety studies will be required in a larger preclinical model to provide reassurance on this issue.

4.3.3 Cell delivery-Another area that needs further development (for all candidate cell types for cardiac therapies) is cell delivery. In preliminary studies, we have found no evidence that hESC-CMs home to injured hearts after intravenous injection (data not shown), nor is there any particular reason to expect these cells to have that capacity. Hence, cardiac therapy with these cells will almost certainly involve their direct delivery to the injured myocardium. Preclinical studies to date with hESC-CMs have involved direct injection via an open thoracotomy, but, moving forward, it would be preferred to deliver these via less-invasive approaches, such as by transvenous [176] or endocardial [177] catheters. Such systems are under development for cardiac cell therapy in general, and often employ guidance by echo, intravascular ultrasound or electrical mapping. hESC-derived preparations may also be deployed in tissue engineered myocardial constructs (discussed further below), and such constructs comprising cells, matrix and polymers may also be injected [178]. As is the case with cell-based cardiac therapies, many delivery parameters will have to be determined empirically, for example, the optimal timing of delivery, cell dose, number of injections (per intervention, and/or possible repeated interventions), injection vehicle, injection volume/cell concentration, and graft placement with respect to the infarct. The ability of hESC-CMs to proliferate in vivo will likely mean that the optimum delivery parameters with this cell type may differ significantly from those determined in clinical trials with other candidate cell types.

4.3.4 Other challenges-Of course, there are still other challenges to the clinical application of hESC-CMs. Some of these are unique to hESC-CMs; others are common to all cell-based cardiac therapies. Of course, of particular concern with all hESC-based therapies is the risk of teratoma formation, and so there is a need for purified preparations of $\mathrm{hESC}-\mathrm{CMs}$, free of undifferentiated hESCs and undesirable non-cardiac derivatives. (In section 3, we discussed multiple strategies to meet this need.) Another problem is the death of the transplanted cells. Indeed, multiple studies have demonstrated that, regardless of the cell type involved, the vast majority of the delivered cells die within the first several days $[179,180]$. 
Some progress has been made on this issue, for example, we have shown that heat shocking hESC-CMs before transplantation [40] and/or delivery of these cells in the presence of a cocktail of pro-survival factors [19] results in larger intracardiac grafts. Overexpression of antiapoptotic proteins is another option, as it has been shown to improve graft survival with other cell types $[14,179]$.

A final challenge, one that applies to all cell-based therapies, is that all such novel therapies must be proven superior to contemporary medical management. Recent decades have seen considerable improvements in the pharmacologic and interventional treatment of patients suffering from acute coronary syndrome and heart failure, and these appear to have had a favorable impact on outcomes [181,182]. This must be kept in mind when evaluating preclinical studies of cell-based therapies in experimental animals (in which case the controls seldom receive the equivalent of modern standardized therapies). Furthermore, because many patients with acute myocardial infarction do well with standardized therapies, we may need new tools to identify those patients that would benefit further from cell-based cardiac therapies (assuming that they are efficacious).

\section{Tissue engineering with hESC-derivatives}

Tissue engineering aims to create a tissue "equivalent" by combining cells within a hierarchical scaffold to impart spatial organization, provide molecular and mechanical cues, and mimic the matrix architecture of the native tissue. Myocardial tissue engineering has received particular interest over the past decade [183], and work is ongoing to incorporate hESCs into these efforts $[72,184,185]$. As mentioned above, in addition to providing cardiomyocytes, $\mathrm{hESCs}$ represent a source of vascular and stromal cells that can be used to develop crucial vascular elements within growing myocardial constructs [186]. Possible myocardial tissue engineering approaches range from injectable self-assembling peptide nanofibers [187], to the production of small cellularized units [188], to the engineering of more organized myocardial structures using naturally-derived or synthetic polymer scaffolds in various forms including sheets, tubes, and pouches [72,187,189-194]. We expect that these technologies will play a role in the development of cell-based cardiac therapies, and that they may eventually result in a vascularized cardiac muscle construct that can be used within or even in place of the infarcted heart.

\section{Summary and future perspectives}

The notion of using stem cells to regenerate the injured heart from its component parts has attracted the interests of many experimental cardiologists as well as the hopes of the large population of patients suffering from ischemic heart disease. We share the optimism of most researchers in this field that ongoing research in cell-based cardiac repair will eventually yield effective clinical therapies. That said, the mixed results from early clinical trials of cell-based cardiac repair with skeletal muscle and bone marrow derived cell preparations demonstrates that the field must continue to refine its approaches and that the ideal cell type for such therapies remains uncertain.

hESCs have tremendous promise as a model system of human cardiac development, a resource for high-throughput screening and safety testing of new drugs, and a potential cell source for cell-based cardiac repair. hESC-CMs have an unambiguous cardiac phenotype, proliferate robustly both in vitro and in vivo. Exciting proof-of-principle for their use in cardiac repair has come from recent studies in rodent infarct models, but substantial challenges remain to their development as a clinically useful cell-based therapy. Without question, they lag behind several candidate adult stem cell sources in testing and development for clinical application. Still, it should be emphasized that it has been less than one decade since the initial report describing 
the isolation of hESCs by Thomson and colleagues [43], and, in our opinion, the field has made good progress in the interim. Improved methods for the maintenance and large-scale expansion of undifferentiated hESCs have been developed. Our group and others have recently developed approaches to efficiently derive cardiomyocytes (and/or other potentially useful cell types) from these cultures. Informed by recent advances in stem cell and developmental biology, progress toward deriving large quantities of even further purified cardiac preparations from hESCs (or related pluripotent cell types [56,57]) seems almost inevitable. Given encouraging preclinical studies with currently available preparations, continued efforts to develop hESCbased cardiac therapies are clearly warranted.

\section{Acknowledgements}

The authors would like to thank Drs. Lil Pabon, Jane Lebkowski and Calvin Harley for helpful comments. We thank Dr. Fernando Santana for assistance in generating the representative fluorescent calcium imaging studies and Shailaja Police for immunocytochemical analysis.

\section{References}

1. Lloyd-Jones DM. The risk of congestive heart failure: sobering lessons from the Framingham Heart Study. Curr Cardiol Rep 2001;3(3):184-90. [PubMed: 11305971]

2. Costanzo MR, et al. Selection and treatment of candidates for heart transplantation. A statement for health professionals from the Committee on Heart Failure and Cardiac Transplantation of the Council on Clinical Cardiology, American Heart Association. Circulation 1995;92(12):3593-612. [PubMed: 8521589]

3. Laflamme MA, Murry CE. Regenerating the heart. Nat Biotechnol 2005;23(7):845-56. [PubMed: 16003373]

4. Dimmeler S, Zeiher AM, Schneider MD. Unchain my heart: the scientific foundations of cardiac repair. J Clin Invest 2005;115(3):572-83. [PubMed: 15765139]

5. Laflamme MA, et al. Cell-based cardiac repair: pathophysiologic mechanisms. Annual Reviews in Pathology (In press). 2007

6. Rubart M, Field LJ. Cardiac regeneration: repopulating the heart. Annu Rev Physiol 2006;68:29-49. [PubMed: 16460265]

7. Menasche P, et al. Autologous skeletal myoblast transplantation for severe postinfarction left ventricular dysfunction. J Am Coll Cardiol 2003;41(7):1078-83. [PubMed: 12679204]

8. Murry CE, et al. Skeletal myoblast transplantation for repair of myocardial necrosis. J Clin Invest 1996;98(11):2512-23. [PubMed: 8958214]

9. Taylor DA, et al. Regenerating functional myocardium: improved performance after skeletal myoblast transplantation. Nat Med 1998;4(8):929-33. [PubMed: 9701245]

10. Orlic D, et al. Bone marrow cells regenerate infarcted myocardium. Nature 2001;410(6829):701-5. [PubMed: 11287958]

11. Shake JG, et al. Mesenchymal stem cell implantation in a swine myocardial infarct model: engraftment and functional effects. Ann Thorac Surg 2002;73(6):1919-25. [PubMed: 12078791]discussion 1926

12. Toma $\mathrm{C}$, et al. Human mesenchymal stem cells differentiate to a cardiomyocyte phenotype in the adult murine heart. Circulation 2002;105(1):93-8. [PubMed: 11772882]

13. Min JY, et al. Significant improvement of heart function by cotransplantation of human mesenchymal stem cells and fetal cardiomyocytes in postinfarcted pigs. Ann Thorac Surg 2002;74(5):1568-75. [PubMed: 12440610]

14. Mangi AA, et al. Mesenchymal stem cells modified with Akt prevent remodeling and restore performance of infarcted hearts. Nat Med 2003;9(9):1195-201. [PubMed: 12910262]

15. Beltrami AP, et al. Adult cardiac stem cells are multipotent and support myocardial regeneration. Cell 2003;114(6):763-76. [PubMed: 14505575]

16. Oh H, et al. Cardiac progenitor cells from adult myocardium: homing, differentiation, and fusion after infarction. Proc Natl Acad Sci U S A 2003;100(21):12313-8. [PubMed: 14530411] 
17. Laugwitz KL, et al. Postnatal is11+ cardioblasts enter fully differentiated cardiomyocyte lineages. Nature 2005;433(7026):647-53. [PubMed: 15703750]

18. Smith RR, et al. Regenerative potential of cardiosphere-derived cells expanded from percutaneous endomyocardial biopsy specimens. Circulation 2007;115(7):896-908. [PubMed: 17283259]

19. Laflamme MA, et al. Cardiomyocytes derived from human embryonic stem cells in pro-survival factors enhance function of infarcted rat hearts. Nat Biotechnol 2007;25(9):1015-1024. [PubMed: 17721512]

20. Leor J, et al. Human embryonic stem cell transplantation to repair the infarcted myocardium. Heart 2007;93(10):1278-84. [PubMed: 17566061]

21. Caspi O, et al. Transplantation of human embryonic stem cell-derived cardiomyocytes improves myocardial performance in infarcted rat hearts. J Am Coll Cardiol 2007;50(19):1884-93. [PubMed: 17980256]

22. van Laake LW, et al. Human embryonic stem cell-derived cardiomyocytes survive and mature in the mouse heart and transiently improve function after myocardial infarction. Stem Cell Research 2007;1 (1):9-24.

23. Tomescot A, et al. Differentiation in vivo of cardiac committed human embryonic stem cells in postmyocardial infarcted rats. Stem Cells 2007;25(9):2200-5. [PubMed: 17540853]

24. Abdel-Latif A, et al. Adult bone marrow-derived cells for cardiac repair: a systematic review and meta-analysis. Arch Intern Med 2007;167(10):989-97. [PubMed: 17533201]

25. Menasche P. Skeletal myoblasts as a therapeutic agent. Prog Cardiovasc Dis 2007;50(1):7-17. [PubMed: 17631434]

26. Schuleri KH, Boyle AJ, Hare JM. Mesenchymal stem cells for cardiac regenerative therapy. Handb Exp Pharmacol 2007;180:195-218. [PubMed: 17554510]

27. Janssens S, et al. Autologous bone marrow-derived stem-cell transfer in patients with ST-segment elevation myocardial infarction: double-blind, randomised controlled trial. Lancet 2006;367(9505): 113-21. [PubMed: 16413875]

28. Lunde K, et al. Intracoronary injection of mononuclear bone marrow cells in acute myocardial infarction. N Engl J Med 2006;355(12):1199-209. [PubMed: 16990383]

29. Meyer GP, et al. Intracoronary bone marrow cell transfer after myocardial infarction: eighteen months' follow-up data from the randomized, controlled BOOST (BOne marrOw transfer to enhance STelevation infarct regeneration) trial. Circulation 2006;113(10):1287-94. [PubMed: 16520413]

30. Schachinger $\mathrm{V}$, et al. Intracoronary bone marrow-derived progenitor cells in acute myocardial infarction. N Engl J Med 2006;355(12):1210-21. [PubMed: 16990384]

31. Reinecke H, Poppa V, Murry CE. Skeletal muscle stem cells do not transdifferentiate into cardiomyocytes after cardiac grafting. J Mol Cell Cardiol 2002;34(2):241-9. [PubMed: 11851363]

32. Murry CE, et al. Haematopoietic stem cells do not transdifferentiate into cardiac myocytes in myocardial infarcts. Nature. 2004

33. Balsam LB, et al. Haematopoietic stem cells adopt mature haematopoietic fates in ischaemic myocardium. Nature. 2004

34. Nygren JM, et al. Bone marrow-derived hematopoietic cells generate cardiomyocytes at a low frequency through cell fusion, but not transdifferentiation. Nat Med 2004;10(5):494-501. [PubMed: 15107841]

35. Xu C, et al. Characterization and enrichment of cardiomyocytes derived from human embryonic stem cells. Circ Res 2002;91(6):501-8. [PubMed: 12242268]

36. Mummery C, et al. Differentiation of human embryonic stem cells to cardiomyocytes: role of coculture with visceral endoderm-like cells. Circulation 2003;107(21):2733-40. [PubMed: 12742992]

37. Kehat I, et al. Human embryonic stem cells can differentiate into myocytes with structural and functional properties of cardiomyocytes. J Clin Invest 2001;108(3):407-14. [PubMed: 11489934]

38. McDevitt TC, Laflamme MA, Murry CE. Proliferation of cardiomyocytes derived from human embryonic stem cells is mediated via the IGF/PI 3-kinase/Akt signaling pathway. J Mol Cell Cardiol 2005;39(6):865-73. [PubMed: 16242146] 
39. Snir M, et al. Assessment of the ultrastructural and proliferative properties of human embryonic stem cell-derived cardiomyocytes. Am J Physiol Heart Circ Physiol 2003;285(6):H2355-63. [PubMed: 14613910]

40. Laflamme MA, et al. Formation of human myocardium in the rat heart from human embryonic stem cells. Am J Pathol 2005;167(3):663-71. [PubMed: 16127147]

41. Evans MJ, Kaufman MH. Establishment in culture of pluripotential cells from mouse embryos. Nature 1981;292(5819):154-6. [PubMed: 7242681]

42. Martin GR. Isolation of a pluripotent cell line from early mouse embryos cultured in medium conditioned by teratocarcinoma stem cells. Proc Natl Acad Sci U S A 1981;78(12):7634-8. [PubMed: 6950406]

43. Thomson JA, et al. Embryonic stem cell lines derived from human blastocysts. Science 1998;282 (5391):1145-7. [PubMed: 9804556]

44. Odorico JS, Kaufman DS, Thomson JA. Multilineage differentiation from human embryonic stem cell lines. Stem Cells 2001;19(3):193-204. [PubMed: 11359944]

45. Xu C, et al. Feeder-free growth of undifferentiated human embryonic stem cells. Nat Biotechnol 2001;19(10):971-4. [PubMed: 11581665]

46. Inzunza J, et al. Derivation of human embryonic stem cell lines in serum replacement medium using postnatal human fibroblasts as feeder cells. Stem Cells 2005;23(4):544-9. [PubMed: 15790775]

47. Yoo SJ, et al. Efficient culture system for human embryonic stem cells using autologous human embryonic stem cell-derived feeder cells. Exp Mol Med 2005;37(5):399-407. [PubMed: 16264264]

48. Xu C, et al. Immortalized fibroblast-like cells derived from human embryonic stem cells support undifferentiated cell growth. Stem Cells 2004;22(6):972-80. [PubMed: 15536188]

49. Xu RH, et al. Basic FGF and suppression of BMP signaling sustain undifferentiated proliferation of human ES cells. Nature Methods 2005;3:185-90. [PubMed: 15782187]

50. Xu C, et al. Basic fibroblast growth factor supports undifferentiated human embryonic stem cell growth without conditioned medium. Stem Cells 2005;23(3):315-23. [PubMed: 15749926]

51. Ludwig TE, et al. Derivation of human embryonic stem cells in defined conditions. Nat Biotechnol 2006;24(2):185-7. [PubMed: 16388305]

52. Li Y, et al. Expansion of human embryonic stem cells in defined serum-free medium devoid of animalderived products. Biotechnol Bioeng 2005;91(6):688-98. [PubMed: 15971228]

53. Bongso A, Tan S. Human blastocyst culture and derivation of embryonic stem cell lines. Stem Cell Rev 2005;1(2):87-98. [PubMed: 17142843]

54. Amit M, Itskovitz-Eldor J. Sources, derivation, and culture of human embryonic stem cells. Semin Reprod Med 2006;24(5):298-303. [PubMed: 17123224]

55. Klimanskaya I, et al. Derivation of human embryonic stem cells from single blastomeres. Nat Protoc 2007;2(8):1963-72. [PubMed: 17703208]

56. Takahashi K, et al. Induction of Pluripotent Stem Cells from Adult Human Fibroblasts by Defined Factors. Cell. 2007

57. Yu J, et al. Induced Pluripotent Stem Cell Lines Derived from Human Somatic Cells. Science. 2007

58. Doetschman TC, et al. The in vitro development of blastocyst-derived embryonic stem cell lines: formation of visceral yolk sac, blood islands and myocardium. J Embryol Exp Morphol 1985;87:2745. [PubMed: 3897439]

59. Norstrom A, et al. Molecular and pharmacological properties of human embryonic stem cell-derived cardiomyocytes. Exp Biol Med (Maywood) 2006;231(11):1753-62. [PubMed: 17138763]

60. Lev S, Kehat I, Gepstein L. Differentiation pathways in human embryonic stem cell-derived cardiomyocytes. Ann N Y Acad Sci 2005;1047:50-65. [PubMed: 16093484]

61. Xu C, et al. Human embryonic stem cell-derived cardiomyocytes can be maintained in defined medium without serum. Stem Cells Dev 2006;15(6):931-41. [PubMed: 17253954]

62. He JQ, et al. Human embryonic stem cells develop into multiple types of cardiac myocytes: action potential characterization. Circ Res 2003;93(1):32-9. [PubMed: 12791707]

63. Dai W, et al. Survival and maturation of human embryonic stem cell-derived cardiomyocytes in rat hearts. J Mol Cell Cardiol 2007;43(4):504-16. [PubMed: 17707399] 
64. Cui L, et al. Structural differentiation, proliferation, and association of human embryonic stem cellderived cardiomyocytes in vitro and in their extracardiac tissues. J Struct Biol 2007;158(3):307-17. [PubMed: 17257857]

65. Maltsev VA, et al. Embryonic stem cells differentiate in vitro into cardiomyocytes representing sinusnodal, atrial and ventricular cell types. Mech Dev 1993;44(1):41-50. [PubMed: 8155574]

66. Sartiani L, et al. Developmental changes in cardiomyocytes differentiated from human embryonic stem cells: a molecular and electrophysiological approach. Stem Cells 2007;25(5):1136-44. [PubMed: 17255522]

67. Satin J, et al. Mechanism of spontaneous excitability in human embryonic stem cell derived cardiomyocytes. J Physiol 2004;559(Pt 2):479-96. [PubMed: 15243138]

68. Dolnikov K, et al. Functional properties of human embryonic stem cell-derived cardiomyocytes. Ann N Y Acad Sci 2005;1047:66-75. [PubMed: 16093485]

69. Dolnikov K, et al. Functional properties of human embryonic stem cell-derived cardiomyocytes: intracellular $\mathrm{Ca} 2+$ handling and the role of sarcoplasmic reticulum in the contraction. Stem Cells 2006;24(2):236-45. [PubMed: 16322641]

70. Friedrich G, Soriano P. Promoter traps in embryonic stem cells: a genetic screen to identify and mutate developmental genes in mice. Genes Dev 1991;5(9):1513-23. [PubMed: 1653172]

71. Weber KT, Brilla CG. Pathological hypertrophy and cardiac interstitium. Fibrosis and reninangiotensin-aldosterone system. Circulation 1991;83(6):1849-65. [PubMed: 1828192]

72. Caspi O, et al. Tissue engineering of vascularized cardiac muscle from human embryonic stem cells. Circ Res 2007;100(2):263-72. [PubMed: 17218605]

73. Ferreira LS, et al. Vascular progenitor cells isolated from human embryonic stem cells give rise to endothelial and smooth muscle like cells and form vascular networks in vivo. Circ Res 2007;101(3): 286-94. [PubMed: 17569886]

74. Levenberg S, et al. Endothelial cells derived from human embryonic stem cells. Proc Natl Acad Sci U S A 2002;99(7):4391-6. [PubMed: 11917100]

75. Huang H, et al. Differentiation of human embryonic stem cells into smooth muscle cells in adherent monolayer culture. Biochem Biophys Res Commun 2006;351(2):321-7. [PubMed: 17069765]

76. Xie CQ, et al. A highly efficient method to differentiate smooth muscle cells from human embryonic stem cells. Arterioscler Thromb Vasc Biol 2007;27(12):e311-2. [PubMed: 18029907]

77. Boheler KR, et al. Differentiation of pluripotent embryonic stem cells into cardiomyocytes. Circ Res 2002;91(3):189-201. [PubMed: 12169644]

78. Garry DJ, Olson EN. A common progenitor at the heart of development. Cell 2006;127(6):1101-4. [PubMed: 17174889]

79. Kelly RG, Brown NA, Buckingham ME. The arterial pole of the mouse heart forms from Fgf10expressing cells in pharyngeal mesoderm. Dev Cell 2001;1(3):435-40. [PubMed: 11702954]

80. Cai CL, et al. Isl1 identifies a cardiac progenitor population that proliferates prior to differentiation and contributes a majority of cells to the heart. Dev Cell 2003;5(6):877-89. [PubMed: 14667410]

81. Kattman SJ, Huber TL, Keller GM. Multipotent flk-1+ cardiovascular progenitor cells give rise to the cardiomyocyte, endothelial, and vascular smooth muscle lineages. Dev Cell 2006;11(5):723-32. [PubMed: 17084363]

82. Moretti A, et al. Multipotent embryonic isl1+ progenitor cells lead to cardiac, smooth muscle, and endothelial cell diversification. Cell 2006;127(6):1151-65. [PubMed: 17123592]

83. Wu SM, et al. Developmental origin of a bipotential myocardial and smooth muscle cell precursor in the mammalian heart. Cell 2006;127(6):1137-50. [PubMed: 17123591]

84. Yatskievych TA, Ladd AN, Antin PB. Induction of cardiac myogenesis in avian pregastrula epiblast: the role of the hypoblast and activin. Development 1997;124(13):2561-70. [PubMed: 9216998]

85. Fullilove SL. Heart induction: distribution of active factors in newt endoderm. J Exp Zool 1970;175 (3):323-6. [PubMed: 5478937]

86. Schultheiss TM, Xydas S, Lassar AB. Induction of avian cardiac myogenesis by anterior endoderm. Development 1995;121(12):4203-14. [PubMed: 8575320]

87. Sugi Y, Lough J. Anterior endoderm is a specific effector of terminal cardiac myocyte differentiation of cells from the embryonic heart forming region. Dev Dyn 1994;200(2):155-62. [PubMed: 7919501] 
88. Ladd AN, Yatskievych TA, Antin PB. Regulation of avian cardiac myogenesis by activin/TGFbeta and bone morphogenetic proteins. Dev Biol 1998;204(2):407-19. [PubMed: 9882479]

89. Sugi Y, Lough J. Activin-A and FGF-2 mimic the inductive effects of anterior endoderm on terminal cardiac myogenesis in vitro. Dev Biol 1995;168(2):567-74. [PubMed: 7729588]

90. Schultheiss TM, Burch JB, Lassar AB. A role for bone morphogenetic proteins in the induction of cardiac myogenesis. Genes Dev 1997;11(4):451-62. [PubMed: 9042859]

91. Schlange T, et al. BMP2 is required for early heart development during a distinct time period. Mech Dev 2000;91(12):259-70. [PubMed: 10704850]

92. Yamashita JK, et al. Prospective identification of cardiac progenitors by a novel single cell-based cardiomyocyte induction. Faseb J 2005;19(11):1534-6. [PubMed: 16033809]

93. Monzen K, et al. Bone morphogenetic proteins induce cardiomyocyte differentiation through the mitogen-activated protein kinase kinase kinase TAK1 and cardiac transcription factors Csx/Nkx-2.5 and GATA-4. Mol Cell Biol 1999;19(10):7096-105. [PubMed: 10490646]

94. Monzen K, et al. Smads, TAK1, and their common target ATF-2 play a critical role in cardiomyocyte differentiation. J Cell Biol 2001;153(4):687-98. [PubMed: 11352931]

95. Angello JC, et al. BMP induction of cardiogenesis in P19 cells requires prior cell-cell interaction(s). Dev Dyn 2006;235(8):2122-33. [PubMed: 16773658]

96. Dono R, et al. The murine cripto gene: expression during mesoderm induction and early heart morphogenesis. Development 1993;118(4):1157-68. [PubMed: 7916676]

97. Johnson SE, Rothstein JL, Knowles BB. Expression of epidermal growth factor family gene members in early mouse development. Dev Dyn 1994;201(3):216-26. [PubMed: 7881126]

98. Xu C, et al. Abrogation of the Cripto gene in mouse leads to failure of postgastrulation morphogenesis and lack of differentiation of cardiomyocytes. Development 1999;126(3):483-94. [PubMed: 9876177]

99. Xu C, et al. Specific arrest of cardiogenesis in cultured embryonic stem cells lacking Cripto-1. Dev Biol 1998;196(2):237-47. [PubMed: 9576836]

100. Parisi S, et al. Nodal-dependent Cripto signaling promotes cardiomyogenesis and redirects the neural fate of embryonic stem cells. J Cell Biol 2003;163(2):303-14. [PubMed: 14581455]

101. Aoki TO, et al. Molecular integration of casanova in the Nodal signalling pathway controlling endoderm formation. Development 2002;129(2):275-86. [PubMed: 11807021]

102. Climent $S$, et al. Neurogenic cells inhibit the differentiation of cardiogenic cells. Dev Biol 1995;171 (1):130-48. [PubMed: 7556890]

103. Antin PB, Taylor RG, Yatskievych T. Precardiac mesoderm is specified during gastrulation in quail. Dev Dyn 1994;200(2):144-54. [PubMed: 7919500]

104. Schultheiss TM, Lassar AB. Induction of chick cardiac myogenesis by bone morphogenetic proteins. Cold Spring Harb Symp Quant Biol 1997;62:413-9. [PubMed: 9598376]

105. Fishman MC, Chien KR. Fashioning the vertebrate heart: earliest embryonic decisions. Development 1997;124(11):2099-117. [PubMed: 9187138]

106. Tzahor E, Lassar AB. Wnt signals from the neural tube block ectopic cardiogenesis. Genes Dev 2001;15(3):255-60. [PubMed: 11159906]

107. Marvin MJ, et al. Inhibition of Wnt activity induces heart formation from posterior mesoderm. Genes Dev 2001;15(3):316-27. [PubMed: 11159912]

108. Schneider VA, Mercola M. Wnt antagonism initiates cardiogenesis in Xenopus laevis. Genes Dev 2001;15(3):304-15. [PubMed: 11159911]

109. Nakamura T, et al. A Wnt- and beta -catenin-dependent pathway for mammalian cardiac myogenesis. Proc Natl Acad Sci U S A 2003;100(10):5834-9. [PubMed: 12719544]

110. Liu Y, et al. Sox 17 is essential for the specification of cardiac mesoderm in embryonic stem cells. Proc Natl Acad Sci U S A 2007;104(10):3859-64. [PubMed: 17360443]

111. Ueno S, et al. Biphasic role for Wnt/beta-catenin signaling in cardiac specification in zebrafish and embryonic stem cells. Proc Natl Acad Sci U S A 2007;104(23):9685-90. [PubMed: 17522258]

112. Naito AT, et al. Developmental stage-specific biphasic roles of Wnt/beta-catenin signaling in cardiomyogenesis and hematopoiesis. Proc Natl Acad Sci U S A 2006;103(52):19812-7. [PubMed: 17170140] 
113. Pandur P, et al. Wnt-11 activation of a non-canonical Wnt signalling pathway is required for cardiogenesis. Nature 2002;418(6898):636-41. [PubMed: 12167861]

114. Terami H, et al. Wnt1 1 facilitates embryonic stem cell differentiation to Nkx2.5-positive cardiomyocytes. Biochem Biophys Res Commun 2004;325(3):968-75. [PubMed: 15541384]

115. Antin PB, et al. Regulation of avian precardiac mesoderm development by insulin and insulin-like growth factors. J Cell Physiol 1996;168(1):42-50. [PubMed: 8647921]

116. Zhu X, et al. Evidence that fibroblast growth factors 1 and 4 participate in regulation of cardiogenesis. Dev Dyn 1996;207(4):429-38. [PubMed: 8950517]

117. Kawai T, et al. Efficient cardiomyogenic differentiation of embryonic stem cell by fibroblast growth factor 2 and bone morphogenetic protein 2. Circ J 2004;68(7):691-702. [PubMed: 15226637]

118. Sachinidis A, et al. Identification of plateled-derived growth factor-BB as cardiogenesis-inducing factor in mouse embryonic stem cells under serum-free conditions. Cell Physiol Biochem 2003;13 (6):423-9. [PubMed: 14631149]

119. $\mathrm{Wu} \mathrm{H}$, et al. Inactivation of erythropoietin leads to defects in cardiac morphogenesis. Development 1999;126(16):3597-605. [PubMed: 10409505]

120. Jankowski M, et al. Rat heart: a site of oxytocin production and action. Proc Natl Acad Sci U S A 1998;95(24):14558-63. [PubMed: 9826739]

121. Paquin J, et al. Oxytocin induces differentiation of P19 embryonic stem cells to cardiomyocytes. Proc Natl Acad Sci U S A 2002;99(14):9550-5. [PubMed: 12093924]

122. Matsuura K, et al. Adult cardiac Sca-1-positive cells differentiate into beating cardiomyocytes. J Biol Chem 2004;279(12):11384-91. [PubMed: 14702342]

123. Danalache BA, et al. Nitric oxide signaling in oxytocin-mediated cardiomyogenesis. Stem Cells 2007;25(3):679-88. [PubMed: 17138963]

124. Rones MS, et al. Serrate and Notch specify cell fates in the heart field by suppressing cardiomyogenesis. Development 2000;127(17):3865-76. [PubMed: 10934030]

125. Chau MD, et al. Notch signaling plays a key role in cardiac cell differentiation. Mech Dev 2006;123 (8):626-40. [PubMed: 16843648]

126. Nemir M, et al. Induction of cardiogenesis in embryonic stem cells via downregulation of Notch1 signaling. Circ Res 2006;98(12):1471-8. [PubMed: 16690879]

127. Lowell S, et al. Notch promotes neural lineage entry by pluripotent embryonic stem cells. PLoS Biol 2006;4(5):e121. [PubMed: 16594731]

128. Passier R, et al. Increased cardiomyocyte differentiation from human embryonic stem cells in serumfree cultures. Stem Cells 2005;23(6):772-80. [PubMed: 15917473]

129. Takahashi T, et al. Ascorbic acid enhances differentiation of embryonic stem cells into cardiac myocytes. Circulation 2003;107(14):1912-6. [PubMed: 12668514]

130. Burridge PW, et al. Improved human embryonic stem cell embryoid body homogeneity and cardiomyocyte differentiation from a novel V-96 plate aggregation system highlights interline variability. Stem Cells 2007;25(4):929-38. [PubMed: 17185609]

131. Shim WS, et al. Ex vivo differentiation of human adult bone marrow stem cells into cardiomyocytelike cells. Biochem Biophys Res Commun 2004;324(2):481-8. [PubMed: 15474453]

132. Fukuda K. Development of regenerative cardiomyocytes from mesenchymal stem cells for cardiovascular tissue engineering. Artif Organs 2001;25(3):187-93. [PubMed: 11284885]

133. Makino S, et al. Cardiomyocytes can be generated from marrow stromal cells in vitro. J Clin Invest 1999;103(5):697-705. [PubMed: 10074487]

134. Rangappa $S$, et al. Transformation of adult mesenchymal stem cells isolated from the fatty tissue into cardiomyocytes. Ann Thorac Surg 2003;75(3):775-9. [PubMed: 12645692]

135. Choi SC, et al. 5-azacytidine induces cardiac differentiation of P19 embryonic stem cells. Exp Mol Med 2004;36(6):515-23. [PubMed: 15665584]

136. Yoon BS, et al. Enhanced differentiation of human embryonic stem cells into cardiomyocytes by combining hanging drop culture and 5-azacytidine treatment. Differentiation 2006;74(4):149-59. [PubMed: 16683985]

137. Edwards MK, Harris JF, McBurney MW. Induced muscle differentiation in an embryonal carcinoma cell line. Mol Cell Biol 1983;3(12):2280-6. [PubMed: 6656767] 
138. Wobus AM, et al. Retinoic acid accelerates embryonic stem cell-derived cardiac differentiation and enhances development of ventricular cardiomyocytes. J Mol Cell Cardiol 1997;29(6):1525-39. [PubMed: 9220339]

139. Mummery C, et al. Cardiomyocyte differentiation of mouse and human embryonic stem cells. J Anat 2002;200(Pt 3):233-42. [PubMed: 12033727]

140. Thomson JA, et al. Embryonic stem cell lines derived from human blastocysts. Science 1998;282:1145-1147. [PubMed: 9804556]

141. Reubinoff BE, et al. Embryonic stem cell lines from human blastocysts: somatic differentiation in vitro. Nat Biotechnol 2000;18(4):399-404. [PubMed: 10748519]

142. Klug MG, et al. Genetically selected cardiomyocytes from differentiating embronic stem cells form stable intracardiac grafts. J Clin Invest 1996;98(1):216-24. [PubMed: 8690796]

143. Zandstra PW, et al. Scalable production of embryonic stem cell-derived cardiomyocytes. Tissue Eng 2003;9(4):767-78. [PubMed: 13678453]

144. Zweigerdt R, et al. Generation of confluent cardiomyocyte monolayers derived from embryonic stem cells in suspension: a cell source for new therapies and screening strategies. Cytotherapy 2003;5(5):399-413. [PubMed: 14578102]

145. Muller M, et al. Selection of ventricular-like cardiomyocytes from ES cells in vitro. Faseb J 2000;14 (15):2540-8. [PubMed: 11099473]

146. Anderson D, et al. Transgenic enrichment of cardiomyocytes from human embryonic stem cells. Mol Ther 2007;15(11):2027-36. [PubMed: 17895862]

147. Huber I, et al. Identification and selection of cardiomyocytes during human embryonic stem cell differentiation. Faseb J 2007;21(10):2551-63. [PubMed: 17435178]

148. Xu C, et al. Cardiac bodies: a novel culture method for enrichment of cardiomyocytes derived from human embryonic stem cells. Stem Cells Dev 2006;15(5):631-9. [PubMed: 17105398]

149. Denning C, et al. Common culture conditions for maintenance and cardiomyocyte differentiation of the human embryonic stem cell lines, BG01 and HUES-7. Int J Dev Biol 2006;50(1):27-37. [PubMed: 16323075]

150. Soonpaa MH, et al. Formation of nascent intercalated disks between grafted fetal cardiomyocytes and host myocardium. Science 1994;264(5155):98-101. [PubMed: 8140423]

151. Koh GY, et al. Stable fetal cardiomyocyte grafts in the hearts of dystrophic mice and dogs. J Clin Invest 1995;96(4):2034-42. [PubMed: 7560097]

152. Leor $\mathbf{J}$, et al. Transplantation of fetal myocardial tissue into the infarcted myocardium of rat. A potential method for repair of infarcted myocardium? Circulation 1996;94(9 Suppl):II332-6. [PubMed: 8901770]

153. Li RK, et al. Cardiomyocyte transplantation improves heart function. Ann Thorac Surg 1996;62(3): 654-60. [PubMed: 8783989]discussion 660-1

154. Scorsin M, et al. Does transplantation of cardiomyocytes improve function of infarcted myocardium? Circulation 1997;96(9 Suppl):II-188-93.

155. Etzion S, et al. Influence of embryonic cardiomyocyte transplantation on the progression of heart failure in a rat model of extensive myocardial infarction. J Mol Cell Cardiol 2001;33(7):1321-30. [PubMed: 11437538]

156. Reinecke H, et al. Survival, integration, and differentiation of cardiomyocyte grafts: a study in normal and injured rat hearts. Circulation 1999;100(2):193-202. [PubMed: 10402450]

157. Min JY, et al. Transplantation of embryonic stem cells improves cardiac function in postinfarcted rats. J Appl Physiol 2002;92(1):288-96. [PubMed: 11744672]

158. Min JY, et al. Long-term improvement of cardiac function in rats after infarction by transplantation of embryonic stem cells. J Thorac Cardiovasc Surg 2003;125(2):361-9. [PubMed: 12579106]

159. Kolossov E, et al. Engraftment of engineered ES cell-derived cardiomyocytes but not BM cells restores contractile function to the infarcted myocardium. J Exp Med 2006;203(10):2315-27. [PubMed: 16954371]

160. Naito H, et al. Xenogeneic embryonic stem cell-derived cardiomyocyte transplantation. Transplant Proc 2004;36(8):2507-8. [PubMed: 15561297] 
161. Menard C, et al. Transplantation of cardiac-committed mouse embryonic stem cells to infarcted sheep myocardium: a preclinical study. Lancet 2005;366(9490):1005-12. [PubMed: 16168783]

162. Hodgson DM, et al. Stable benefit of embryonic stem cell therapy in myocardial infarction. Am J Physiol Heart Circ Physiol 2004;287(2):H471-9. [PubMed: 15277190]

163. Behfar A, et al. Stem cell differentiation requires a paracrine pathway in the heart. Faseb J 2002;16 (12):1558-66. [PubMed: 12374778]

164. Nussbaum J, et al. Transplantation of undifferentiated murine embryonic stem cells in the heart: teratoma formation and immune response. Faseb J 2007;21(7):1345-57. [PubMed: 17284483]

165. Swijnenburg RJ, et al. Embryonic stem cell immunogenicity increases upon differentiation after transplantation into ischemic myocardium. Circulation 2005;112(9 Suppl):I166-72. [PubMed: 16159810]

166. Kehat I, et al. Electromechanical integration of cardiomyocytes derived from human embryonic stem cells. Nat Biotechnol 2004;22(10):1282-9. [PubMed: 15448703]

167. Xue $\mathrm{T}$, et al. Functional integration of electrically active cardiac derivatives from genetically engineered human embryonic stem cells with quiescent recipient ventricular cardiomyocytes: insights into the development of cell-based pacemakers. Circulation 2005;111(1):11-20. [PubMed: 15611367]

168. Kofidis T, et al. Allopurinol/uricase and ibuprofen enhance engraftment of cardiomyocyte-enriched human embryonic stem cells and improve cardiac function following myocardial injury. Eur J Cardiothorac Surg 2006;29(1):50-5. [PubMed: 16337396]

169. Xie CQ, et al. Transplantation of human undifferentiated embryonic stem cells into a myocardial infarction rat model. Stem Cells Dev 2007;16(1):25-9. [PubMed: 17348803]

170. Leobon B, et al. Myoblasts transplanted into rat infarcted myocardium are functionally isolated from their host. Proc Natl Acad Sci U S A 2003;100(13):7808-11. [PubMed: 12805561]

171. Halbach M, et al. Electrophysiological maturation and integration of murine fetal cardiomyocytes after transplantation. Circ Res 2007;101(5):484-92. [PubMed: 17641227]

172. Rubart M, et al. Physiological coupling of donor and host cardiomyocytes after cellular transplantation. Circ Res 2003;92(11):1217-24. [PubMed: 12730096]

173. Rubart M, et al. Spontaneous and evoked intracellular calcium transients in donor-derived myocytes following intracardiac myoblast transplantation. J Clin Invest 2004;114(6):775-83. [PubMed: 15372101]

174. Drukker M, et al. Human embryonic stem cells and their differentiated derivatives are less susceptible to immune rejection than adult cells. Stem Cells 2006;24(2):221-9. [PubMed: 16109762]

175. van den Brandt J, Kovacs P, Kloting I. Blood pressure, heart rate and motor activity in 6 inbred rat strains and wild rats (Rattus norvegicus): a comparative study. Exp Anim 1999;48(4):235-40. [PubMed: 10591002]

176. Thompson CA, et al. Left ventricular functional recovery with percutaneous, transvascular direct myocardial delivery of bone marrow-derived cells. J Heart Lung Transplant 2005;24(9):1385-92. [PubMed: 16143261]

177. Oron U, et al. Technical delivery of myogenic cells through an endocardial injection catheter for myocardial cell implantation. Int J Cardiovasc Intervent 2000;3(4):227-230. [PubMed: 12431347]

178. Wang CC, et al. Direct intramyocardial injection of mesenchymal stem cell sheet fragments improves cardiac functions after infarction. Cardiovasc Res. 2007

179. Zhang M, et al. Cardiomyocyte grafting for cardiac repair: graft cell death and anti-death strategies. J Mol Cell Cardiol 2001;33(5):907-21. [PubMed: 11343414]

180. Muller-Ehmsen J, et al. Survival and development of neonatal rat cardiomyocytes transplanted into adult myocardium. J Mol Cell Cardiol 2002;34(2):107-16. [PubMed: 11851351]

181. Fox KA, et al. Decline in rates of death and heart failure in acute coronary syndromes, 1999-2006. Jama 2007;297(17):1892-900. [PubMed: 17473299]

182. Levy D, et al. Long-term trends in the incidence of and survival with heart failure. N Engl J Med 2002;347(18):1397-402. [PubMed: 12409541]

183. Jawad H, et al. Myocardial tissue engineering: a review. J Tissue Eng Regen Med 2007;1(5):32742. [PubMed: 18038427] 
184. Zimmermann WH, Eschenhagen T. Embryonic stem cells for cardiac muscle engineering. Trends Cardiovasc Med 2007;17(4):134-40. [PubMed: 17482096]

185. Alperin C, Zandstra PW, Woodhouse KA. Engineering cardiac healing using embryonic stem cellderived cardiac cell seeded constructs. Front Biosci 2007;12:3694-712. [PubMed: 17485332]

186. Levenberg S, et al. Endothelial potential of human embryonic stem cells. Blood 2007;110(3):80614. [PubMed: 17412888]

187. Davis ME, et al. Custom design of the cardiac microenvironment with biomaterials. Circ Res 2005;97 (1):8-15. [PubMed: 16002755]

188. Chen $\mathrm{CH}$, et al. Construction and characterization of fragmented mesenchymal-stem-cell sheets for intramuscular injection. Biomaterials 2007;28(31):4643-51. [PubMed: 17673287]

189. Blan NR, Birla RK. Design and fabrication of heart muscle using scaffold-based tissue engineering. J Biomed Mater Res A. 2007

190. Franchini JL, et al. Novel tissue engineered tubular heart tissue for in vitro pharmaceutical toxicity testing. Microsc Microanal 2007;13(4):267-71. [PubMed: 17637075]

191. Masuda S, et al. Cell sheet engineering for heart tissue repair. Adv Drug Deliv Rev. 2007

192. Radisic M, et al. Biomimetic approach to cardiac tissue engineering. Philos Trans R Soc Lond B Biol Sci 2007;362(1484):1357-68. [PubMed: 17594967]

193. Radisic M, et al. Pre-treatment of synthetic elastomeric scaffolds by cardiac fibroblasts improves engineered heart tissue. J Biomed Mater Res A. 2007

194. Yildirim Y, et al. Development of a biological ventricular assist device: preliminary data from a small animal model. Circulation 2007;116(11 Suppl):I16-23. [PubMed: 17846298] 

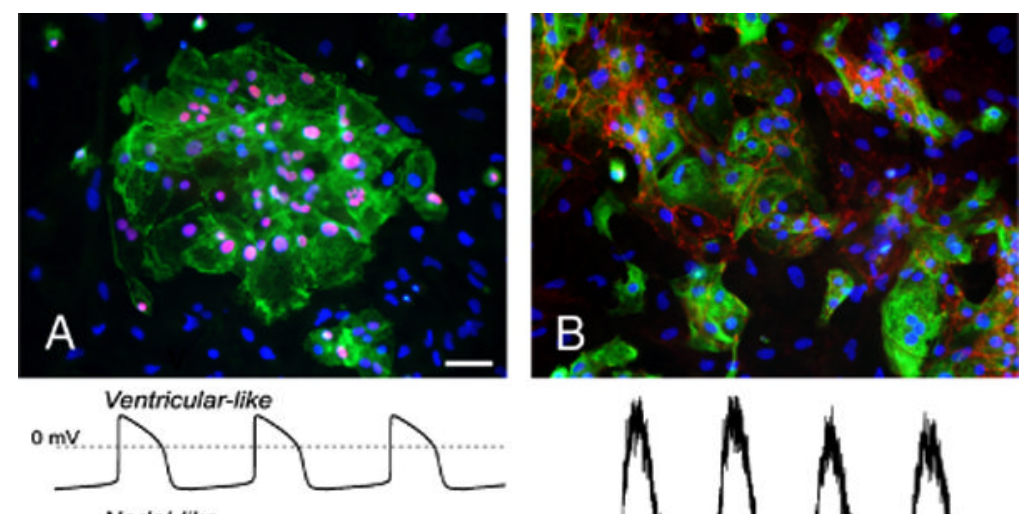

Nodal-like

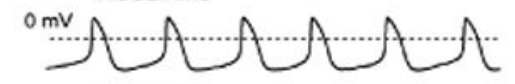
Atrial-like

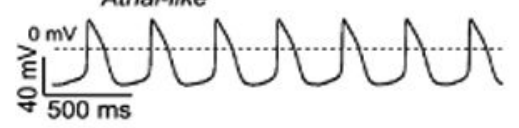

C

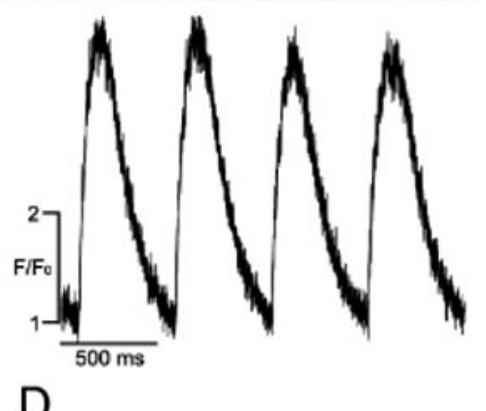

Figure 1. Human embryonic stem cell derived cardiomyocytes (hESC-CMs) exhibit an unambiguous cardiac phenotype

A-B. hESC-CMs express expected cardiac-specific markers, as demonstrated by immunocytochemical analysis. A: cardiac troponin I (green) and Nkx2.5 (red). B: sarcomeric myosin heavy chain (green) and N-cadherin (red). Nuclei were stained with DAPI (blue). Bar=50 $\mu \mathrm{m}$.

C. hESC-CMs exhibit expected electrophysiologic properties and, as illustrated by these representative current-clamp recordings, include cardiomyocytes with distinct ventricular-, nodal-, and atrial-like action potential properties.

D. In response to depolarization (in this case, by field stimulation at 1Hz), hESC-CMs exhibit $\left[\mathrm{Ca}^{2+}\right]_{\mathrm{i}}$ transients that can be detected with the fluorescent calcium rhod-4 AM. (from unpublished data by Zhu, Santana, and Laflamme) 


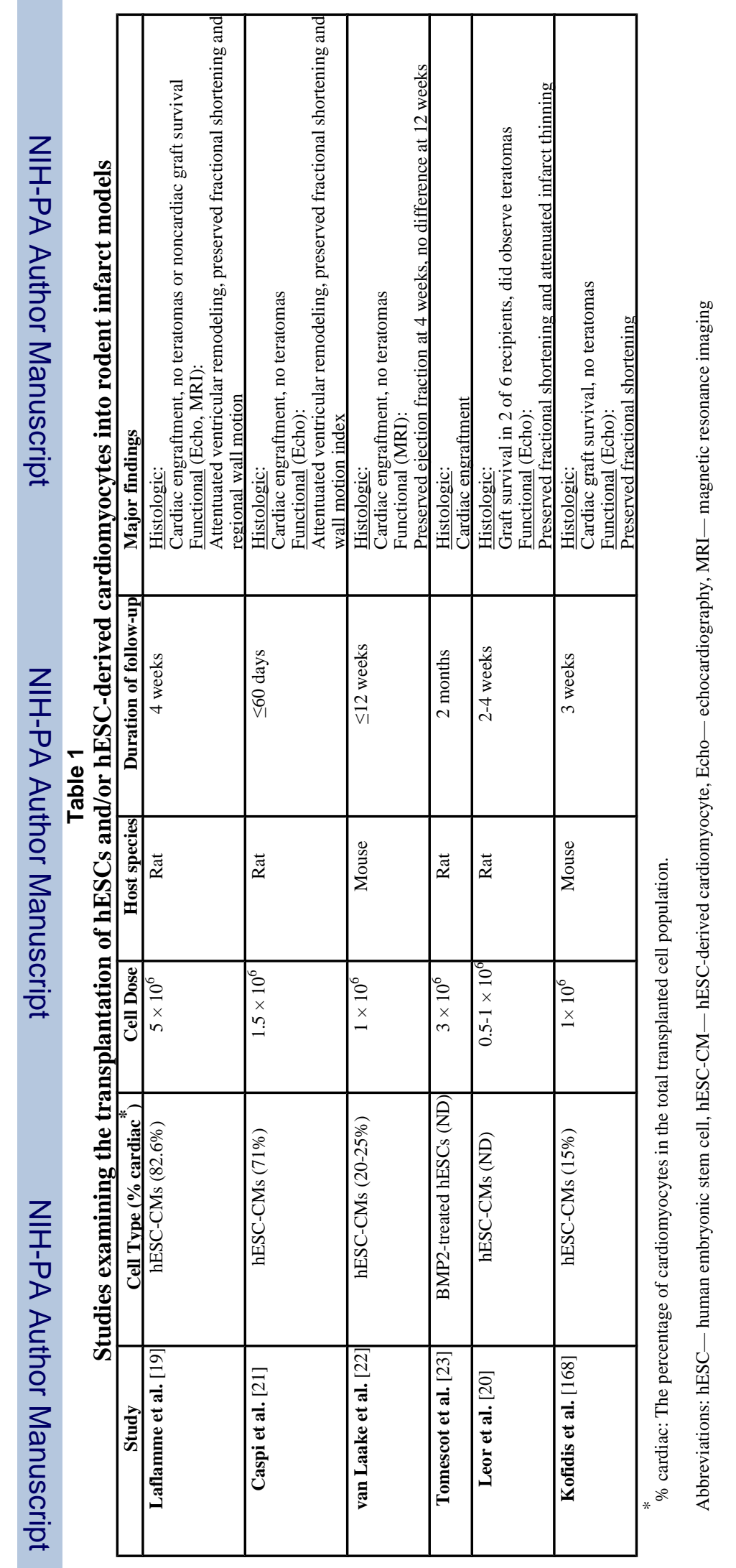

Transplant Rev (Orlando). Author manuscript; available in PMC 2010 January 1. 